\title{
ÍNDICE DE MATERIAS
}

Págs.

Reglas fundamentales para la exploración de las embarazadas y parturientas.

Dlagnóstico y exploración durante el primer periodo del embarazo (meses pri-

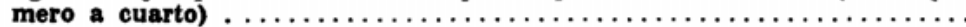

Diagnóstico del primer período del EMbarazo $\ldots \ldots \ldots \ldots \ldots \ldots$ I. Los cuatro signos vaginales (pág. 3). II. Signos uterinos (pág. 4). A. Signos del cuerpo uterino (pág. 4). B. Signos del segmento infeferior del útero y del cuello uterino (pág. 9).

EXPLORACIÓN EN EL PRIMER PERÍodo DEL EMBARAZo........... Anamnesis (pág. 14). A. Nombre, edad, paridad (pág. 14). B. Antecedentes tocológicos (pág. 14). C. Datos acerca del embarazo (página 15). D. Antecedentes patológicos (pág. 20).

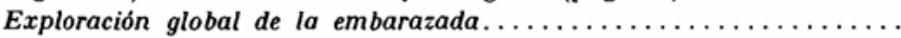

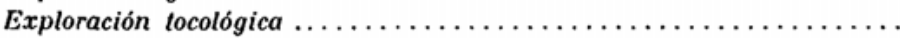

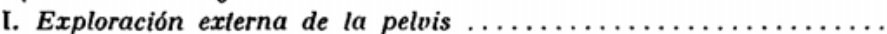
Maniobras de Baumm (pág. 22). Maniobra por separación de los dedos (pág. 24). Pelvimetría (pág. 25).

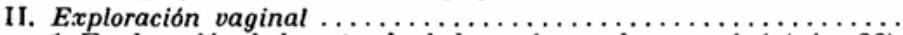
1. Exploración de la entrada de la vagina, vulva y periné (pág. 28). 2. Exploración con el espéculo (pág. 29). 3. Tacto vaginal (pág. 29). 4. Exploración bimanual (pág. 29).

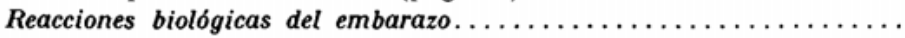

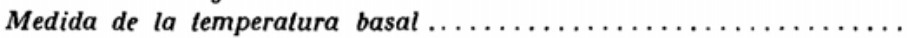

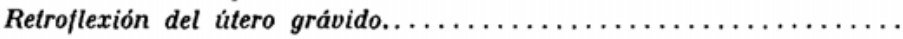

Palpación de la pelvis (pág. 35). Determinación del diámetro conjugado verdadero (pág. 37). Determinación del ángulo púbico (página 38).

Diagnóstlco y exploración del embarazo entre los meses quinto y décimo... .

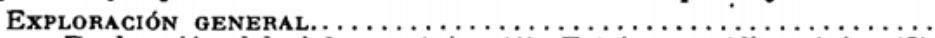

Exploración del abdomen (pág. 41). Estrías gravidicas (pág. 42). Pigmentaciones del embarazo (pág. 43). Hipertricosis gravidica (página 43). Edemas y varices (pág. 43).

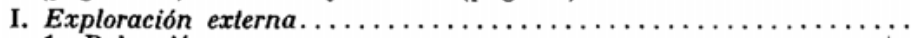

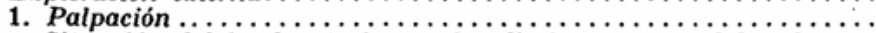
Situación del fondo uterino en los distintos meses del embarazo (página 44). Descenso del fondo uterino (pág. 45). Diferenciación entre el octavo y décimo meses de embarazo (pág. 45). Maniobras de Leopold (pág. 49). Medios auxiliares de la palpación (página 53). Conceptos fundamentales: situación, posición, actitud y presentación (pág. 55).

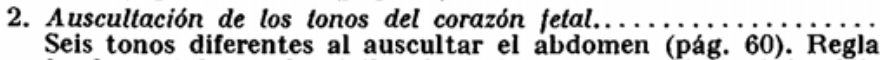
fundamental para la vigilancia de los tonos cardiacos (pág. 61).

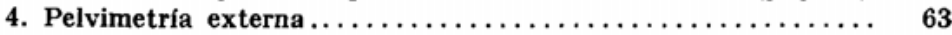

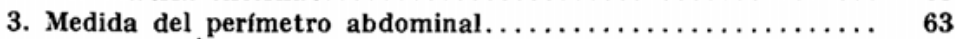

5. Exploración roentgenológica $\ldots \ldots \ldots \ldots \ldots \ldots \ldots \ldots \ldots \ldots \ldots \ldots \ldots \ldots \ldots$ 


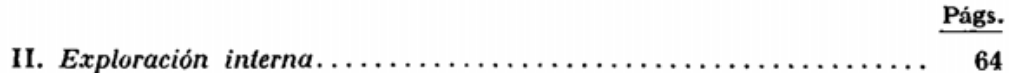

III. Examen de la orina, presión arterial $y$ peso $\ldots \ldots \ldots \ldots \ldots \ldots \ldots$

Exploración de los factores sanguíneos................. 68

Resumen de los signos del embarazo . . . . . . . . . . . $\ldots \ldots$

Diferenciación entre primíparas y multíparas $\ldots \ldots \ldots \ldots \ldots \ldots \ldots \ldots \quad 71$

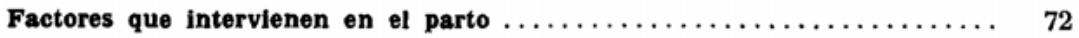

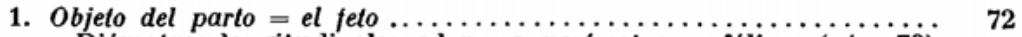

Diámetros longitudinales, planos y perímetros cefálicos (pág. 73).

Diámetros transversales cefálicos (pág. 74). Signos cefálicos en las exploraciones externa e interna (pág. 74). Diferenciación de las fontanelas mayor y menor (pág. 75). Medidas importantes del tronco fetal (pág. 76).

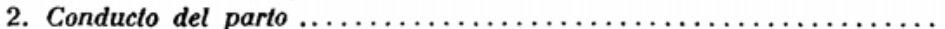

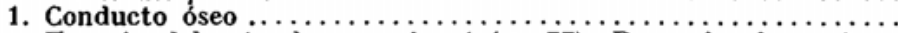
Espacio del estrecho superior (pág. 77). Denominaciones tocológicas de dirección (pág. 78). Cavidad pélvica (pág. 80). Sistema clásico de planos (pág. 80). Estrecho inferior (pág. 81). Sistema de planos paralelos, según Hodge (pág. 82).

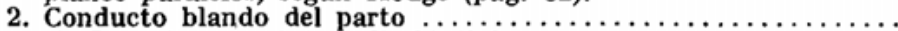
a) Tubo interno (pág. 83). b) Tubo externo (pág. 84).

3. Fuerzas del parto (fuerzas expulsivas o contracciones) ........... Propiedades de las contracciones (pág. 87). Tipos de las contracciones (página 87). ¿Cómo se producen las contracciones? (pág. 88).

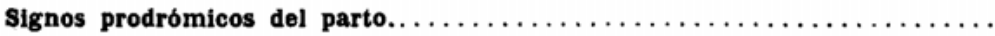

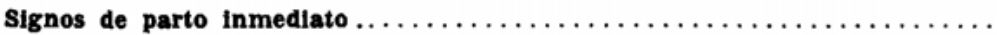

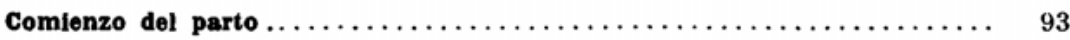

Preparación de la embarazada para el parto $\ldots \ldots \ldots \ldots \ldots \ldots \ldots \ldots \ldots$

Exploración de la parturlenta $\ldots \ldots \ldots \ldots \ldots \ldots \ldots \ldots \ldots \ldots \ldots \ldots \ldots$

Anamnesis junto a la cama de la parturienta $\ldots \ldots \ldots \ldots \ldots \ldots$

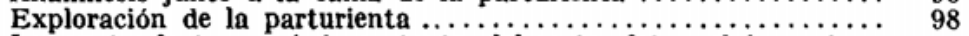

Los cuatro factores más importantes del parto : feto, pelvis, contracciones uterinas y dilatación del orificio uterino (pág. 99). Exploración global y exploración tocológica (pág. 99). Exploración rectal (página 101). Exploración vaginal (pág. 103). Indicaciones de la exploración vaginal durante el parto (pág. 103). ¿Cuándo debe evitar el médico general la exploración vaginal? (pág. 105). Esquema para efectuar la exploración rectal (vaginal) (pág. 106).

Actitud de la cabeza durante su paso por el conducto del parto ........

I. Entrada en el estrecho superior (mecanismo de entrada) .......

II. Paso a través de la cavidad pélvica (mecanismo de paso) ......

III. Mecanismo de salida del conducto del parto $\ldots \ldots \ldots \ldots \ldots \ldots \ldots$

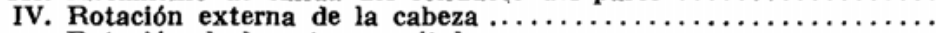
Rotación de la sutura sagital .

Diagnóstico del nivel de la cabeza fetal $\ldots \ldots \ldots \ldots \ldots \ldots \ldots \ldots \ldots$

A. Comprobación de la altura por medio de la exploración ExTERNA. Sinopsis de las maniobras Externas para determinar la altura de

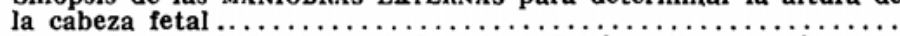

B. Comprobación de la altura de la cabeza fetal mediante exploración

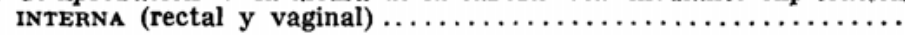

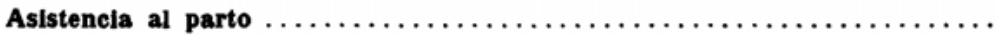

1. Asistencia durante el periodo de dilatacion $\ldots \ldots \ldots \ldots \ldots \ldots \ldots$ Signos y efecto de las contracciones dilatantes (pág. 127). Posición de la parturienta (pág. 129). Regla general sobre la posición de la parturienta (pág. 130). Rotura de la bolsa de las aguas (pág. 130). Analgesia en el perfodo de dilatación (pág. 134). Hipoalgesia por inhalación con tricloretilo (pág. 135). 
2. Asistencia durante el periodo expulsivo $\ldots \ldots \ldots \ldots \ldots \ldots \ldots \ldots, 135$

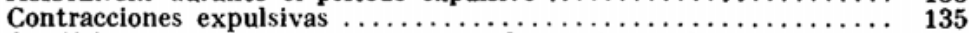

Condiciones previas importantes para la ayuda con la prensa abdominal (pág. 136). Posición adecuada (pág. 137). Preparación adecuada para contraer la prensa abdominal (pág. 137). Aprovechamiento adecuado de las contracciones de la prensa abdominal (página 138). Tumor serosanguíneo (caput succedaneum) (pág. 139). Céfalohematoma (pág. 142).

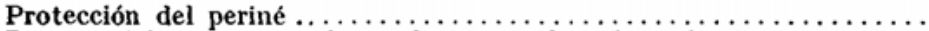

Dos maniobras para acelerar el paso de la cabeza fetal ...........

1. Maniobra de Ritgen $=$ maniobra de periné posterior $\ldots \ldots \ldots \ldots$

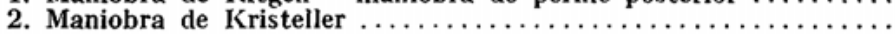

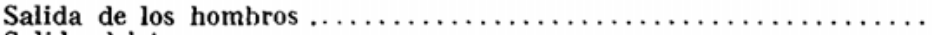

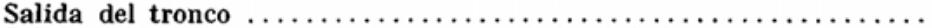

Salida de las caderas $\mathbf{y}$ de las extremidades inferiores $\ldots \ldots \ldots \ldots \ldots$

Analgesia durante el período expulsivo $\ldots \ldots \ldots \ldots \ldots \ldots \ldots \ldots \ldots$

Signos de madurez fetal $\ldots \ldots \ldots \ldots \ldots \ldots \ldots \ldots \ldots \ldots \ldots \ldots \ldots$

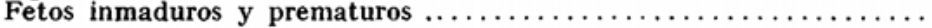

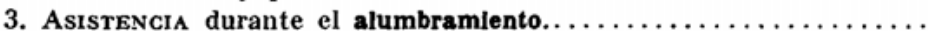
Desprendimiento y expulsión de la placenta (pág. 152). Modalidades del desprendimiento placentario: modalidad de B. S. S. Schultze, modalidad de Duncan (pág. 153). ¿Qué debe hacer el médico durante el alumbramiento? (pág. 153). 1. Observar el estado general de la madre (pág. 154). 2. Observar la hemorragia fisiológica del alumbramiento (pág. 155). 3. Observar el útero (pág. 155). 4. Comprobar la altura del fondo uterino (pág. 156).

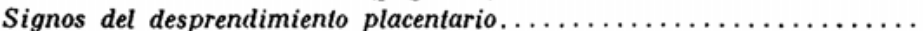
A. Signo uterino, de C. Schroeder (pág. 157). B. Signos del cordón umbilical (pág. 157). C. Signo placentario (peso sobre el ano) (pág. 158). Maniobra de Credé (pág. 159). ¿Qué no ha de hacer el médico durante el alumbramiento? (pág. 162).

Resumen de la asistencia durante el alumbramiento............... Comprobación de la integridad de la placenta (pág. 166). 1. Examen de las membranas (pág. 166). 2. Examen de la cara fetal (amniótica) de la placenta (pág. 167). 3. Examen de la cara materna (decidual) de la placenta (pág. 168).

Duración del parto

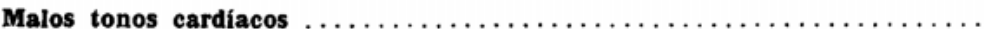

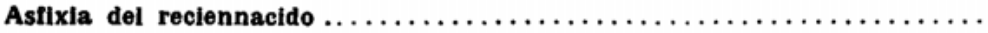

División de la asfixia según Flagg. Asfixia de primer hasta de tercer grado (pág. 173). Causas (pág. 174). Tratamiento (pág. 174). 1. Las vías respiratorias han de estar libres de obstáculos (pág. 175). Técnica para introducir la sonda en la tráquea: a) La introducción a ciegas (pág. 176). b) La introducción mediante el laringoscopio (página 177). 2. Respiración forzada, con sobrepresión (pág. 177). Respiración forzada, boca a boca (pág. 179). Tratamiento medicamentoso (pág. 180).

Inercia uterina

Inercia uterina primaria $\ldots \ldots \ldots \ldots \ldots \ldots \ldots \ldots \ldots \ldots \ldots \ldots \ldots \ldots$

Inercia uterina secundaria $\ldots \ldots \ldots \ldots \ldots \ldots \ldots \ldots \ldots \ldots \ldots \ldots \ldots \ldots$

Tratamiento de la inercia uterina $\ldots \ldots \ldots \ldots \ldots \ldots \ldots \ldots \ldots \ldots \ldots$ División de los oxitócicos (pág. 184). 1. Medicamentos sensibilizantes del útero (pág. 184). 2. a) Medicamentos para obtener contracciones uterinas en los períodos dilatante y expulsivo (pág. 185). Principios fundamentales para la prescripción de oxitócicos (pág. 186). Atascamiento del parto (pág. 188). 2. b) Tónicos uterinos (pág. 189). 3. Espasmolíticos (pág. 190). 4. Medicamentos para combatir el agotamiento (pág; 190). 
Págs.

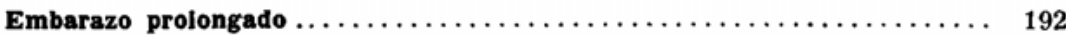

Signos de alarma en caso de embarazo prolongado .......... 193

Iniciación $y$ aceleración del parto $\ldots \ldots \ldots \ldots \ldots \ldots \ldots \ldots \ldots \ldots \ldots \ldots \ldots$

I. Indicaciones que justifican la iniciación del parțo (pág. 194). II. Indicaciones para acelerar el parto (pág. 195). Iniciación y aceleración del parto con medicamentos (pág. 195). Iniciación y aceleración quirúrgica del parto (pág. 198). Técnica de la rotura artificial de la bolsa (pág. 196). 1. Rotura de la bolsa por vía vaginal (página 196). Método de Drew-Smythe (pág. 197). 2. Rotura de la bolsa por vía rectovaginal (pág. 198).

Detencion del parto en el suelo de la pelvis $\ldots \ldots \ldots \ldots \ldots \ldots \ldots \ldots \ldots$

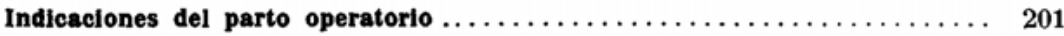

Grupo primero de indicaciones : peligros para la madre . . . . . . . . 203

Grupo segundo de indicaciones: peligros para el feto .......... 207

Preparativos para las operaciones tocologicas $\ldots \ldots \ldots \ldots \ldots \ldots \ldots \ldots \ldots$

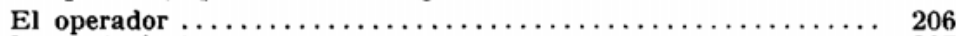

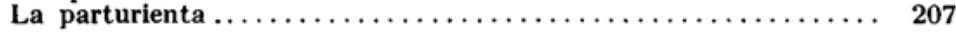

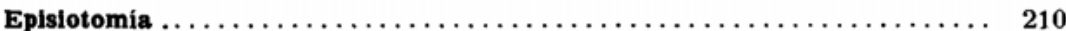

Sutura de la herida por la episiotomía $\ldots \ldots \ldots \ldots \ldots \ldots \ldots \ldots \ldots$

Desgarros del periné $=$ desgarros perineovaginales $\ldots \ldots \ldots \ldots \ldots \ldots \ldots \ldots 216$

Sutura del desgarro perineal de primer grado (pág. 218). Sutura del desgarro perineal de tercer grado (pág. 219). Tratamiento consecutivo de los desgarros perineales (pág. 221).

Desgarros del clítoris $y$ de los labios

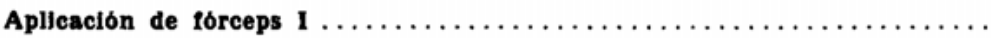

Condiciones previas para la aplícación de fórceps (pág. 223). Reglas fundamentales para la aplicación de fórceps (pág. 226). Dificultades para la articulación del fórceps (pág. 231).

Aplicación de tórceps II (Fórceps con cabeza en posición oblicua) ..... 236

Pellgros y pronóstico de la apllcaclón del fórceps $\ldots \ldots \ldots \ldots \ldots \ldots \ldots \ldots$

Actitudes y situación anómalas de la cabeza $\ldots \ldots \ldots \ldots \ldots \ldots \ldots \ldots \ldots$

1. Situación transversal profunda de la cabeza $\ldots \ldots \ldots \ldots \ldots \ldots \ldots \ldots$

2. Situación alta ántero-posterior de la cabeza $\ldots \ldots \ldots \ldots \ldots \ldots \ldots \ldots$

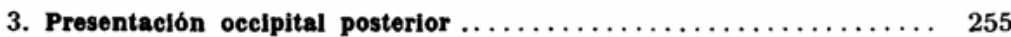

4. Presentaciones en deflexión (presentaciones en extensión) $\ldots \ldots \ldots 268$

Primera presentación en deflexion. Presentación de sincipucio... 270

Segunda presentación en deflexión. Presentación de frente....... 279

Tercera presentación en deflexión. Presentación de cara........ 283

Sinopsis de las presentaclones celálicas normales y anormales ...... 294

Presentación de extremidad pélvica $\ldots \ldots \ldots \ldots \ldots \ldots \ldots \ldots \ldots \ldots \ldots$

Exploración externa (pág. 298). Exploración interna (pág. 299). Diagnóstico diferencial (pág. 301). Necesidad de la exploración vaginal en las presentaciones de extremidad pélvica (pág. 302). Mecanismo del parto en la presentación de nalgas (pág. 303). Peligros de la presentación de extremidad pélvica (pág. 313). Asistencia al parto en la presentación de extremidad pélvica (pág. 316). A. Método de elección: tratamiento conservador (pág. 316). B. Parto, mediante cesárea, en la presentación de extremidad pélvica (pág 318). C. Descenso profiláctíco de un pie (pág. 320.). 


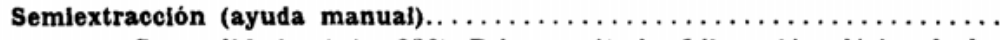
Generalidades (pág. 320). Primer método. Liberación clásica de los brazos y maniobra de Veit-Smellie para la extracción de la cabeza (página 322). Segundo método. Liberación de los brazos según A. Mueller, seguida de la maniobra de Veit-Smellie para la extracción de la cabeza (pág. 329). Tercer método. I.iberación de los brazos y extracción de la cabeza según Bracht (pág. 331). Aplicación de los distintos métodos (pág. 333). Aplicación de fórceps en la cabeza última (pág. 334).

Extracción completa (extracción manual)

Condiciones previas (pág. 335). Primer caso. Presentación de pies incompleta, con procidencia del pie anterior (pág. 336). Segundo caso. Presentación de pies incompleta, con procidencia del pie posterior (pág. 341). Tercer caso. Presentación de pies completa (página 342). (Cuarto caso. Presentación de nalgas y pies (pág. 342). Quinto caso. Presentación de rodillas (pág. 343). Sexto caso. Presentación genuina de nalgas (pág. 343). Hacer descender el pie anterior (pág. 343). Dificultades para el descenso de un pie: maniobra de Pinard (pág. 345).

Medios auxiliares para la extracción inmediata por las nalgas........

Resumen de las reglas para realizar la extracción completa en la presen-

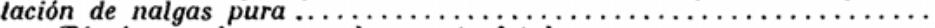

Técnica en los casos de muerte fetal segura ..............

Dificultades en la extracción completa $\ldots \ldots \ldots \ldots \ldots \ldots \ldots \ldots \ldots \ldots$ A. Dificultades en la liberación de los brazos (pág. 351). B. Dificultades en la extracción de la cabeza (pág. 355). Maniobra de Veitkel (pág. 356). Maniobra de Praga, invertida (pág. 358). Fórceps en la cabeza última (pág. 359).

Episiotomía profunda $=$ Incisión vaginoperineal y del suclo pélvico $=$ Inci-

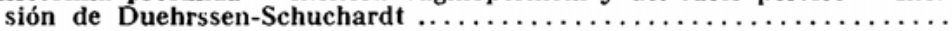

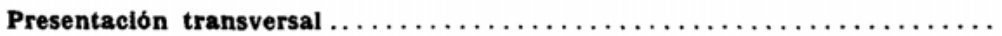

División, frecuencia, etíología (pág. 362). Pronóstico, mortalidad (página 363). Curso del parto en presentación transversal, tres fases (página 365). láase primera = bolsa de las aguas intacta (pág. 365). Fase segunda $=$ fase peligrosa. Comienza en el momento de la rotura de la bolsa (pág. 372). Modo de actuar en el prolapso del brazo (página 381). Modo de actuar en el prolapso del cordón umbilical (página 383). Fase tercera = fase catastrófica, o fase de S. O. S. (página 384). Indicaciones para la cesárea en presentación transversal (página 390).

Metreurisis

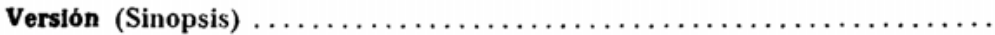

Versión externa en la presentación transversal $\ldots \ldots \ldots \ldots \ldots \ldots \ldots \ldots \ldots$

Versión interna o combinada en la presentación transversal ............

Condiciones previas (pág. 397). Momento para efectuar la versión (página 399). Modo de efectuar la versión (pág. 399). Elección de la mano interna (pág. 401). Diferencias entre la mano y el pie (página 405). Pausa entre la versión y la extracción (pág. 407). La versión no es posible. ¿Qué hacemos? (pág. 407). Doble maniobra de J. Siegmundin (pág. 408).

Operaciones de fragmentación, I. Decapitación y embriotomía..........

Gemelos ...........................................

Frecuencia, Diagnóstico (pág. 415). Embarazo, curso del parto (página 418). Complicaciones (pág. 419). Asistencia al parto (pá- 
gina 420). Nacimiento del primer gemelo (pág. 420). Nacimiento del segundo gemelo (pág. 421). ¿Qué debe hacerse después de la expulsión del primer gemelo? (pág. 421). Alumbramiento (pág. 424).

Gemelos univitelinos 0 bivitelinos . . . . . $\ldots \ldots \ldots \ldots \ldots \ldots \ldots$

Procedencia del cordón umbllical $\ldots \ldots \ldots \ldots \ldots \ldots \ldots \ldots \ldots \ldots \ldots \ldots \ldots \ldots$

Prolapso del cordón umbllical $\ldots \ldots \ldots \ldots \ldots \ldots \ldots \ldots \ldots \ldots \ldots \ldots \ldots \ldots$

Conducta que se ha de seguir en las diferentes presentaciones .. 431

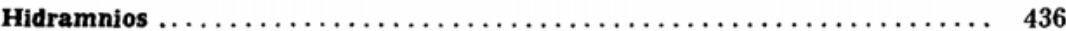

Síntomas principales (pág. 437). Diagnóstico diferencial (pág. 439). Tratamiento (pág. 440).

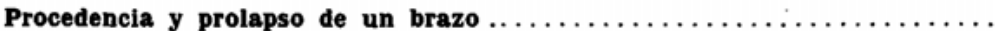
441

Hemorragias patologicas durante el embarazo y el parto (Resumen) . . . . 447

Aborto

Causas maternas (pág. 448). Causas ovulares (pág. 450). Causas paternas (pág. 459). Mecanismo y curso del aborto (pág. 451). Clínica del aborto (pág. 454). Aborto completo (pág. 454). Aborto incompleto (pág. 455). Aborto incipiente (pág. 456). Aborto inminente (pág. 457). Aborto habitual (pág. 460). Missed abortion (página 461). Aborto febril (pág. 462). Aborto séptico (pág. 463). Reglas para efectuar el legrado (pág. 463).

Listerosis 466

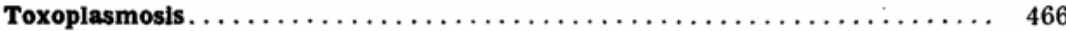

Mola vesiculosa (mola hidatidica) $\ldots \ldots \ldots \ldots \ldots \ldots \ldots \ldots \ldots \ldots \ldots, 467$

Carioepitelioma.............................. 474

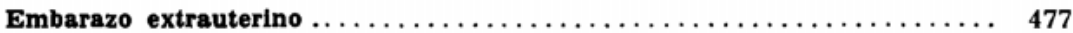

Diagnóstico del embarazo tubárico intacto (pág. 480). Diagnóstico de la rotura tubárica (pág. 482). Tipos de hemorragía (pág. 483). Diagnóstico del aborto tubárico (pág. 485).

Placenta previa

Frecuencia (pág. 490). Síntomas clínicos (pág. 490). Diagnóstico diferencial (pág. 491). División habitual de la placenta previa en grados (pág. 493). Tratamiento (pág. 494).

Desprendimiento prematuro de la placenta normalmente insertada....... Frecuencia y causas (pág. 507). Sintomas típicos de un caso grave (página 509). Tratamiento (pág. 511).

Versión interna o combinada en la presentación cefálica.............. 516

Versión con dos dedos, según Braxton Hicks $\ldots \ldots \ldots \ldots \ldots \ldots \ldots \ldots \ldots, 521$

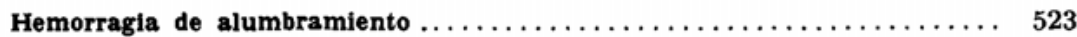

Hemorragia atónica (pág. 523). Hemorragia por desgarro (página 523). Causas de la atonía (pág. 525). Hemorragia atónica antes de la expulsión de la placenta (pág. 526). Dificultades en el desprendimiento manual de la placenta (pág. 531). Hemorragia atónica después de la expulsión de la placenta (pág. 532).

Desgarro del cuello uterino $\ldots \ldots \ldots \ldots \ldots \ldots \ldots \ldots \ldots \ldots \ldots \ldots \ldots, 544$

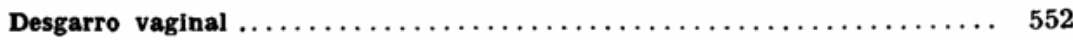

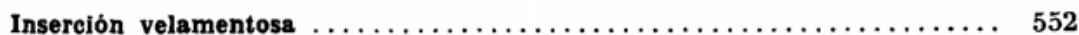


Diagnóstico anatómico (pág. 557). Diagnóstico funcional (pág. 558). Formas más importantes de pelvis estrecha (pág. 562). Pronóstico del parto en las pelvis estrechas (pág. 576). Complicaciones (página 579). Lesiones (pág. 581). Asistencia al parto (pág. 584). Tratamiento quirúrgico (pág. 595).

Hidrocéfalo

Rotura uterina

División (pág. 610). Rotura uterina por hiperdistensión (pág. 613). Amenaza de rotura uterina (pág. 603). Rotura uterina consumada (página 617).

Operaciones de fragmentación, II. Perforación y craneotraxia $\ldots \ldots \ldots \ldots$ 621

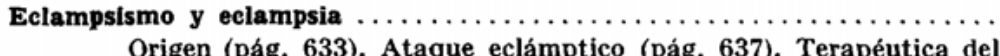
631 eclampsismo (pág. 639). Edemas (pág. 639). Hipertensión y nefropatía (pág. 640). Terapéutica de la eclampsia (pág. 640). Tres tipos de tratamiento en la eclampsia (pág. 641). Terapéutica conservadora de la eclampsia (pág. 644). Fenotiacinas (pág. 645). Derivados de la ftalacina (pág. 645). Preparados de veratrum (pág. 646). Bloqueadores ganglionares (pág. 646). Éster de la colina (pág. 646). Dieta (pág. 648). Medios deshidratantes (pág. 650). Complicaciones de la eclampsia (pág. 651).

Apéndice : Parto por medio de valvas

fNDICE ALFABÉtICo. 
